\title{
Epidemiologic and clinical characteristics of neonates with late-onset COVID-19: 1-year data of Turkish Neonatal Society
}

\author{
Ilke Mungan Akin ${ }^{1}$ (D) Mehmet Kenan Kanburoglu ${ }^{2} \cdot$ Cuneyt Tayman $^{3} \cdot$ Mehmet Yekta Oncel $^{4,5}$.

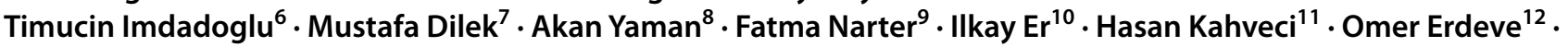 \\ Esin $\mathrm{Koc}^{13} \cdot$ Neo-Covid Study Group
}

Received: 6 September 2021 / Revised: 16 December 2021 / Accepted: 19 December 2021 / Published online: 21 January 2022

(c) The Author(s), under exclusive licence to Springer-Verlag GmbH Germany, part of Springer Nature 2022

\begin{abstract}
The literature on neonates with SARS-CoV-2 is mainly concerned with perinatal cases, and scanty data are available about environmentally infected neonates. To fill knowledge gaps on the course and prognosis of neonatal cases, we analyzed 1-year data from the Turkish Neonatal Society in this prospective cohort study of neonates with postnatal transmission. Data from 44 neonatal intensive care units (NICUs), of neonates with positive RT-PCR results at days 5-28 of life, were extracted from the online registry system and analyzed. Of 176 cases, most were term infants with normal birth weight. Fever was the most common symptom (64.2\%), followed by feeding intolerance (25.6\%), and cough (21.6\%). The median length of hospitalization was 9 days, with approximately one quarter of infants receiving some type of ventilatory support. Myocarditis (5.7\%) was the most common complication during follow-up. Among the clinical findings, cough (odds ratio [OR]: 9.52, 95\% confidence interval [CI]: 4.17-21.71), tachypnea (OR: 26.5, 95\% CI: 9.59-73.19), and chest retractions (OR: 27.5, 95\% CI: 5.96-126.96) were associated with more severe clinical disease. Also, there were significant differences in the C-reactive protein level, prothrombin time (PT), partial thromboplastin time, international normalized ratio, and days in the NICU $(p=0.002, p=0.012, p=0.034, p=0.008$, and $p<0.001$, respectively) between patients with mild-moderate and severe-critical presentations. A PT above $14 \mathrm{~s}$ was a significant predictor of severe/critical cases, with a sensitivity of $64 \%$ and specificity of $73 \%$.

Conclusions: Our data showed that late-onset COVID-19 infection in neonates who need hospitalization can be severe, showing associations with high rates of ventilatory support and myocarditis. Cough, tachypnea, and retractions on admission suggest a severe disease course.

Trial registration: ClinicalTrials.gov identifier: NCT04401540.

\section{What is Known:}

- Neonatal cases of COVID-19 infection are mainly reported as perinatal COVID-19 cases.

- Neonates with perinatal transmission have a mild course and favorable prognosis.

What is New:

- Among symptomatic neonates with late-onset COVID-19 infection, fever was the most common symptom, and almost one quarter of hospitalized cases needed some type of respiratory support. Myocarditis was the most common complication.

- The presence of cough, tachypnea, retractions, and a PT above $14 \mathrm{~s}$ were associated with an increased risk of severe COVID-19.
\end{abstract}

Keywords SARS-CoV-2 $\cdot$ COVID-19 $\cdot$ Newborn $\cdot$ Postnatal

\begin{tabular}{lll} 
& \multicolumn{2}{l}{ Abbreviations } \\
& COVID-19 & Coronavirus disease 2019 \\
\cline { 1 - 2 } Communicated by Daniele De Luca & CRP & C-reactive protein \\
\cline { 1 - 2 } $\begin{array}{ll}\text { Ilke Mungan Akin } \\
\text { ilkemungan@gmail.com }\end{array}$ & CT & Computerized tomography \\
Extended author information available on the last page of the article & INR & Electronic case report forms \\
& GIS & Gastrointestinal system \\
& INR & International normalized ratio
\end{tabular}




\begin{tabular}{|c|c|}
\hline NICU & Neonatal intensive care unit \\
\hline PT & Prothrombin time \\
\hline PTT & Partial thromboplastin time \\
\hline RT-PCR & $\begin{array}{l}\text { Reverse transcriptase-polymerase c } \\
\text { reaction }\end{array}$ \\
\hline SARS-CoV-2 & $\begin{array}{l}\text { Severe acute respiratory syndrome } \\
\text { coronavirus- } 2\end{array}$ \\
\hline TNS & Turkish Neonatal Society \\
\hline WHO & World Health Organization \\
\hline
\end{tabular}

\section{Introduction}

During the novel coronavirus 2019 (COVID-19) pandemic caused by severe acute respiratory syndrome coronavirus 2 (SARS-CoV-2), millions of people have been hospitalized and many have died $[1,2]$. The worldwide medical community has deployed its considerable resources to acquire knowledge about the virus, including how it spreads, the characteristics and course of the infection, and avenues for treatment and prevention (e.g., through vaccines) [3].

In the early stages of the pandemic, the likely presentation in neonates was unclear, as data from Chinese sources were scarce; even the route of transmission was uncertain. Vertical transmission, particularly in mothers with a positive SARS-CoV-2 reverse transcriptase-polymerase chain reaction (RT-PCR) test in the last 14 days of pregnancy, was evaluated in various articles [4-9]. As some articles reported on lower expression of nasal epithelial SARS-CoV-2 entry receptors in newborns, postnatal horizontal transmission may have been overlooked [10, 11].

To fill knowledge gaps on the course and prognosis of neonatal cases of SARS-CoV-2 infection, the incidence, symptoms, and severity should be thoroughly documented and reported to enable creation of a database, along with rational, evidence-based management guidelines. In our previous study, we reported the data of 37 symptomatic neonates with postnatal horizontal transmission during the early pandemic period; here, we report 1-year data for neonates with postnatal horizontal transmission from the Turkish Neonatal Society (TNS), including previously published cases [12].

\section{Materials and methods}

On March 2020, after the World Health Organization (WHO) declared COVID-19 a pandemic, the TNS conducted a multicenter prospective observational cohort study and established an online registry for late-onset neonatal COVID-19 cases who had RT-PCR-proven SARS-CoV-2 infection after 5 days of birth, as defined by
Sankaran et al. [13]. Clinical directors in neonatal intensive care units (NICUs) nationwide were made aware of this study, and 44 NICUs from 32 cities in Turkey participated. The NICUs were asked to add all neonates admitted to the emergency room or outpatient clinics meeting the inclusion criteria to the online registry system. Records between March 2020 and February 2021 were pooled and analyzed. Management of newborns with, or at risk of, COVID-19 was in accordance with the guidelines of the TNS and Turkish Ministry of Health [14, 15].

In the presence of high-risk factors such as fever, hypoxia (oxygen saturation $<92 \%$ ), feeding intolerance, and lethargy, newborns were admitted to an isolation room or designated area for COVID-19 patients within the NICU. Access to the patients' rooms and care thereof were in accordance with the recommendations of the TNS [14].

Nasopharyngeal/oropharyngeal swabs were obtained on admission, and every 2 days thereafter, using a kit from Bioeksen (Istanbul, Turkey) and following the WHO guidelines for performing RT-PCR in laboratories certified by the Ministry of Health.

The decision to breastfeed was made on a case-by-case basis after consulting with the parents, until the WHO provided definitive guidance on June 23, 2020 (16). In response to increasing knowledge of breastmilk safety, mothers were encouraged to breastfeed their infants while wearing a face mask after careful handwashing, or to express their breast milk to establish a supply.

\section{Case definitions}

Neonates aged 5-28 days with positive RT-PCR results were included in this study; RT-PCR samples were taken from neonates with symptoms and/or a history of COVID19 contact after birth. Patients were classified according to the presence of respiratory and non-respiratory symptoms, and in terms of disease severity (as defined by Dong et al.) (17). All neonates, regardless of whether they were admitted to an NICU, were followed up, and contact tracing was implemented by the Ministry of Health for at least 14 days.

Data were recorded in electronic case report forms using the online data registry system (www. trials-network.org), including demographic, epidemiologic, and clinical features; medical history (congenital malformations, antenatal, natal, and postnatal risk factors, and perinatal course); treatments; breastfeeding history; and any recent contact with COVID-19 patients. Signs and symptoms including fever, cough, respiratory distress, vomiting, feeding intolerance, diarrhea, irritability, and somnolence were recorded. Laboratory and radiological examination results were investigated. Supportive treatments include fluids and electrolytes, empirical antibiotic therapy until sepsis was ruled out, and oxygen therapy and advanced respiratory support with mechanical ventilation were recorded. Patients were 


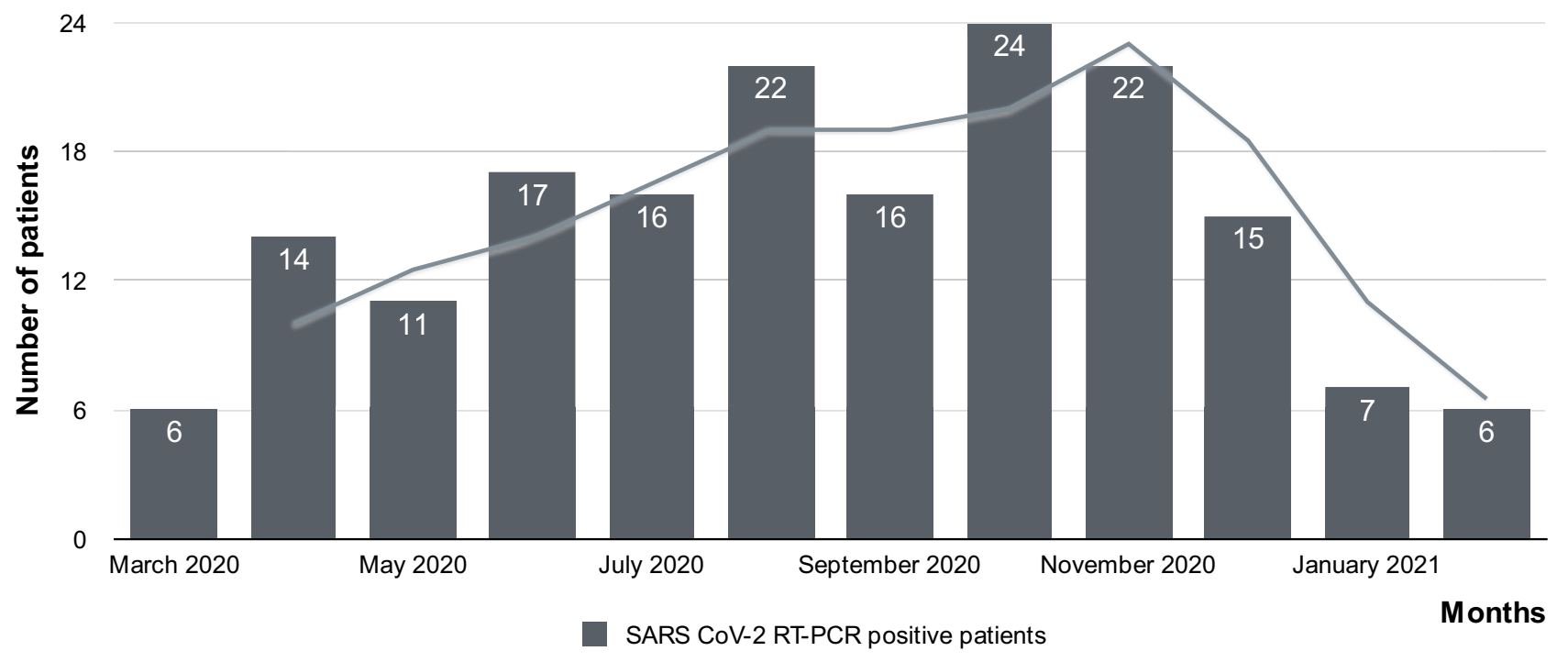

Fig. 1 Distribution of late-onset neonatal COVID-19 cases during one year period

discharged according to discharge criteria defined by the TNS [14]. Length of hospitalization, complications, and mortality were also recorded.

\section{Ethics approval}

The study was approved by the Online Studies Scientific Steering Committee of the TNS, the Institutional Review Board of Rize University School of Medicine, and the Review Board of the Ministry of Health. Written informed consent was obtained from the parents or guardians of the newborns.

\section{Statistical analyses}

Statistical analyses were performed using the SPSS statistical software for Windows (ver. .21.0; SPSS Inc., Chicago, IL, USA). Continuous values are presented as the mean \pm standard deviation (SD), or as median (range) according to the homogeneity of the distribution, which was evaluated by the Kolmogorov-Smirnov test. Student's $t$-test was used for analyzing continuous variables with a normal distribution, and the Mann-Whitney $U$ and Kruskal-Wallis tests were used for analyzing continuous variables that did not exhibit a normal distribution. Categorical data are presented as numbers $(n)$ and frequencies (\%), and were analyzed by the $\chi^{2}$ test. A $p$-value of $<0.05$ was considered statistically significant.

\section{Role of the funding source}

This study was supported by the TNS, which funded the online registration system used by the study. The TNS had no role in the study design, data analysis, decision to publish, or preparation of the article. The corresponding author had full access to all the data in the study and took final responsibility for the decision to submit the manuscript for publication. The final version of the manuscript was approved by all authors. No honorarium, grant, or other form of funding was provided to any author in connection with the study.

\section{Results}

The data of 198 neonates were extracted from the online registry system. Of these, 22 were excluded due to inappropriate or inadequate data, such that the data of 176 neonates were included in the analysis and the distribution of these cases during one year period is analyzed (Fig. 1). The majority of the patients (93.2\%) were from urban areas, and 50\% were from the two biggest cities in Turkey (Istanbul and Ankara) (Table 1).

Table 1 Demographic characteristics of neonates with RT-PCR proven SARS-CoV-2 infection

\begin{tabular}{ll}
\hline & Results \\
\hline Gestational age $($ wks) $($ mean \pm SD) & $38.2 \pm 1.6$ \\
Birth weight $(\mathrm{g})($ mean \pm SD) & $3219 \pm 506$ \\
AGA infants $(n, \%)$ & $157(89.2)$ \\
Sex, female $(n, \%)$ & $70(39.8)$ \\
Delivery mode, vaginal delivery $(n, \%)$ & $91(51.7)$ \\
Age at admission (days) (mean \pm SD) & $15.3 \pm 7.6$ \\
Source of infection & \\
Unknown $(n, \%)$ & $30(17)$ \\
Family members within the same house $(n, \%)$ & $137(77.8)$ \\
$\quad$ RT PCR positivity in mother $(n, \%)$ & $116(65.9)$ \\
Someone other than family members $(n, \%)$ & $7(4)$ \\
Nosocomial $(n, \%)$ & $2(1.1)$ \\
Healthcare worker parent $(n, \%)$ & $7(4)$ \\
Number of people in the house $(n)($ median, min-max) & $4(2-10)$ \\
\hline
\end{tabular}

$w k s w e e k s, g$ gram, $A G A$ appropriate for gestational age 
Table 2 Clinical features of neonates with RT-PCR proven SARSCoV-2 infection and admitted to hospital

\begin{tabular}{|c|c|c|}
\hline Complaints & $n(\%)$ & \\
\hline Asymptomatic & $19(10.8)$ & \\
\hline Fever & $113(64.2)$ & \\
\hline Only fever & $45(25.6)$ & \\
\hline + Any respiratory symptoms & $23(13.1)$ & \\
\hline + Any GIS symptoms & $23(13.1)$ & \\
\hline + Respiratory and GIS symptoms & $11(6.2)$ & \\
\hline + Somnolence/irritability & $5(2.8)$ & \\
\hline Feeding intolerance & $45(25.6)$ & \\
\hline Cough & $38(21.6)$ & \\
\hline Tachypnea & $33(18.8)$ & \\
\hline Retractions & $22(12.5)$ & \\
\hline Diarrhea & $14(8)$ & \\
\hline Rhinorrhea & $14(8)$ & \\
\hline Somnolence/Irritability & $13(7.4)$ & \\
\hline Rash & $3(1.7)$ & \\
\hline Hospitalization ( $n, \%)$ & $170(96.6)$ & \\
\hline Chest CT $(n, \%)$ & $8(4.5)$ & \\
\hline Groundglass/consolidation & $4(2.2)$ & \\
\hline \multicolumn{3}{|l|}{ Complications } \\
\hline Myocarditis $(n, \%)$ & $10(5.7)$ & \\
\hline $\operatorname{DIC}(n, \%)$ & $1(0.6)$ & \\
\hline Multiple organ dysfunction $(n, \%)$ & $1(0.6)$ & \\
\hline \multicolumn{3}{|l|}{ Feeding type } \\
\hline Breastfeeding with PPE $(n, \%)$ & $31(17.6)$ & \\
\hline Expressed milk with PPE $(n, \%)$ & $90(51.1)$ & \\
\hline Breastfeeding without PPE $(n, \%)$ & $13(7.4)$ & \\
\hline Formula $(n, \%)$ & $42(23.9)$ & \\
\hline Treatment & & $\begin{array}{l}\text { Duration } \\
\text { (median, } \\
\text { min-max) }\end{array}$ \\
\hline No treatment $(n, \%)$ & $69(39.2)$ & \\
\hline Antibiotic treatment $(n, \%)$ (days) & $95(54)$ & $7(2-26)$ \\
\hline Azithromycin treatment $(n, \%)$, (days) & $29(16.5)$ & $5(1-10)$ \\
\hline Oseltamivir treatment $(n, \%)$, (days) & $15(8.5)$ & $5(5-7)$ \\
\hline \multicolumn{3}{|l|}{ Respiratory support } \\
\hline Oxygen supplementation $(n, \%)(\mathrm{h})$ & $47(26.7)$ & $58(8-504)$ \\
\hline nCPAP requirement $(n, \%)(\mathrm{h})$ & $17(9.6)$ & $47(6-456)$ \\
\hline Mechanical ventilation $(n, \%)(\mathrm{h})$ & $8(4.5)$ & $47.5(5-494)$ \\
\hline Hospitalization (days) & & $9(1-70)$ \\
\hline
\end{tabular}

GIS gastrointestinal system, $C T$ computed tomography, DICdisseminated intravascular coagulation, $P P E$ personal protective equipment, $n C P A P$ nasal continuous airway pressure

The mean gestational age was $38.2 \pm 1.6$ weeks, and the mean birth weight was $3,219 \pm 506 \mathrm{~g}$. Of the 176 patients, 91 (51.7\%) were born via vaginal delivery. The median Apgar scores were 8 and 9 at 1 and 5 min after birth, respectively. The mean diagnosis time was $15.4 \pm 7.6$ days after birth. The source of infection was known in 146 (83\%) cases (infected by a family
Table 3 Laboratory findings of neonates with RT-PCR proven SARS$\mathrm{CoV}-2$ infection

\begin{tabular}{|c|c|}
\hline Laboratory parameters & $\begin{array}{l}\text { Mean } \pm \text { SD or } \\
\text { median (min- } \\
\text { max) }\end{array}$ \\
\hline Leukocyte count $(n=171) / \mu \mathrm{L}$ & $10,464 \pm 5959$ \\
\hline $\begin{array}{l}\text { Neutrophil count }(n=171) / \mu \mathrm{L} \\
\text { Neutropenia }(<1500 / \mu \mathrm{L})(n, \%)\end{array}$ & $\begin{array}{l}3570 \pm 2303 \\
33(19.2)\end{array}$ \\
\hline $\begin{array}{l}\text { Lymphocyte count }(n=171) / \mu \mathrm{L} \\
\text { Lymphopenia }(<1500 / \mu \mathrm{L})(n, \%)\end{array}$ & $\begin{array}{l}4921 \pm 3226 \\
10(5.8)\end{array}$ \\
\hline Thrombocyte count $(n=171) \times 10^{3} / \mu \mathrm{L}$ & $332 \pm 119$ \\
\hline Hemoglobin $(\mathrm{Hb})(n=171) \mathrm{g} / \mathrm{dl}$ & $13.9 \pm 2.7$ \\
\hline $\begin{array}{l}\text { C-reactive protein }(\mathrm{CRP})(n=171) \mathrm{mg} / \mathrm{L} \\
\text { Elevated CRP }(>5 \mathrm{mg} / \mathrm{L})(n, \%)\end{array}$ & $\begin{array}{l}1.2(0.1-71.9) \\
31(18.1)\end{array}$ \\
\hline $\begin{array}{l}\text { Interleukin-6 (IL-6) }(n=35) \mathrm{pg} / \mathrm{mL} \\
\text { Elevated IL-6 }(>44.4 \mathrm{pg} / \mathrm{mL})(n, \%)\end{array}$ & $\begin{array}{l}21(1.5-796) \\
7(20)\end{array}$ \\
\hline $\begin{array}{l}\text { Procalcitonin }(n=90) \mathrm{ng} / \mathrm{mL} \\
\text { Elevated Procalcitonin }(>0.5 \mathrm{ng} / \mathrm{mL})(n, \%)\end{array}$ & $\begin{array}{l}0.15(0.01-270) \\
36(40)\end{array}$ \\
\hline Alanine aminotransferase (ALT) $(n=168) \mathrm{U} / \mathrm{L}$ & $23(10-580)$ \\
\hline Aspartate aminotransferase (AST) $(n=168) \mathrm{U} / \mathrm{L}$ & $40.5(10-478)$ \\
\hline$\gamma$-Glutamyl transferase (GGT) $(n=88) \mathrm{U} / \mathrm{L}$ & $96.5(11-550)$ \\
\hline Lactate dehydrogenase (LDH) $(n=124) \mathrm{U} / \mathrm{L}$ & $432.8 \pm 149.9$ \\
\hline Blood urea nitrogen $(\mathrm{BUN})(n=165) \mathrm{mg} / \mathrm{dl}$ & $11.9 \pm 9.2$ \\
\hline Creatinine $(n=167) \mathrm{mg} / \mathrm{dl}$ & $0.39 \pm 0.18$ \\
\hline Albumin $(n=145) \mathrm{g} / \mathrm{dl}$ & $3.5 \pm 0.4$ \\
\hline Creatinine kinase $(\mathrm{CK})(n=84) \mathrm{U} / \mathrm{L}$ & $116,5(4-1002)$ \\
\hline Troponin $\mathrm{T}(n=72) \mathrm{ng} / \mathrm{ml}$ & $24.3(0.01-2557)$ \\
\hline Prothrombin time $(\mathrm{PT})(n=104) \mathrm{s}$ & $13.4 \pm 2.8$ \\
\hline Partial thromboplastin time (PTT) $(n=104) \mathrm{s}$ & $35 \pm 13.5$ \\
\hline International normalized ratio (INR) $(n=104)$ & $1.1 \pm 0.2$ \\
\hline Fibrinogen $(n=58) \mathrm{mg} / \mathrm{dl}$ & $276.8 \pm 117.3$ \\
\hline
\end{tabular}

member living within the same house, $n=137$ (77.8\%); infected by an individual other than a family member, $n=7(4 \%)$ ). Only two $(1.1 \%)$ cases were nosocomial in origin (Table 1$)$.

In total, 157 (89.2\%) neonates were admitted to hospital with at least one of the predefined symptoms. Fever was the most common complaint in $113(64.2 \%)$ patients, followed by feeding intolerance $(n=45,25.6 \%)$, cough $(n=38$, $21.6 \%)$, tachypnea $(n=33,18.8 \%)$, chest retractions $(n=22$, $12.5 \%)$, and diarrhea $(n=14,8 \%)$. Fever was sometimes accompanied by respiratory $(n=23,13.1 \%)$ or gastrointestinal symptoms $(n=23,13.1 \%)$. A rash was present in only three infants (1.7\%), without any accompanying symptoms; in one of these patients, there were clinical and laboratory findings of myocarditis during follow-up (Table 2). All laboratory findings are summarized in Table 3 .

Of the infants, 170 were hospitalized, with a median stay of 9 days (range: 1-70 days). Breastmilk was available for $134(76.1 \%)$ patients, either via breastfeeding or expressed breastmilk (Table 4). In total, 69 infants $(39.2 \%)$ did not receive any specific treatment, while 95 (54\%) received antibiotics including ampicillin, gentamicin, vancomycin, 
Table 4 Patient clinical and laboratory findings according to their severity

\begin{tabular}{|c|c|c|c|}
\hline & $\begin{array}{l}\text { Mild-Moderate } \\
n=112\end{array}$ & $\begin{array}{l}\text { Severe-critical } \\
n=45\end{array}$ & $p$ \\
\hline Gestational age $($ weeks $)($ mean \pm SD $)$ & $38.3 \pm 1.4$ & $37.9 \pm 2.0$ & 0.730 \\
\hline Birth weight $(g)($ mean \pm SD $)$ & $3239 \pm 430$ & $3127 \pm 664$ & 0.455 \\
\hline Sex, female $(n, \%)$ & $44(39.3)$ & $19(42.2)$ & 0.876 \\
\hline Age at admission (days) $($ mean \pm SD) & $15.1 \pm 7.5$ & $16.3 \pm 7.8$ & 0.409 \\
\hline $\begin{array}{l}\text { Number of people in the house }(n) \text { (median, } \\
\text { min-max) }\end{array}$ & $4.2 \pm 1.4$ & $4.8 \pm 1.6$ & 0.012 \\
\hline Fever & $82(73.2)$ & $31(68.9)$ & 0.727 \\
\hline Feeding intolerance & $30(26.8)$ & $15(33.3)$ & 0.532 \\
\hline Cough & $13(11.6)$ & $25(55.6)$ & $<0.001$ \\
\hline Tachypnea & $6(5.4)$ & $27(60)$ & $<0.001$ \\
\hline Retractions & $2(1.8)$ & $20(44.4)$ & $<0.001$ \\
\hline Diarrhea & $11(9.8)$ & $3(6.7)$ & 0.751 \\
\hline Rhinorrhea & $10(8.9)$ & $4(8.9)$ & 1 \\
\hline Somnolence/Irritability & $3(2.7)$ & $1(2.2)$ & 1 \\
\hline Leukocyte count $(/ \mu \mathrm{L})$ & $10,399 \pm 6789$ & $10,491 \pm 4445$ & 0.454 \\
\hline Neutrophil count $(/ \mu \mathrm{L})$ & $3412 \pm 2180$ & $3996 \pm 2681$ & 0.266 \\
\hline Lymphocyte count $(/ \mu \mathrm{L})$ & $4953 \pm 3478$ & $4611 \pm 2939$ & 0.378 \\
\hline Thrombocyte count $\left(\times 10^{3} / \mu \mathrm{L}\right)$ & $329 \pm 116$ & $332 \pm 125$ & 0.767 \\
\hline Hemoglobin (Hb) (g/dl) & $13.9 \pm 2.5$ & $13.6 \pm 3.1$ & 0.461 \\
\hline C-reactive protein $(\mathrm{CRP})(\mathrm{mg} / \mathrm{L})$ & $2.9 \pm 7.7$ & $9.1 \pm 16.4$ & 0.002 \\
\hline Alanine aminotransferase (ALT) (U/L) & $38.2 \pm 62.1$ & $26.6 \pm 15.3$ & 0.333 \\
\hline Aspartate aminotransferase (AST) (U/L) & $54.2 \pm 51.8$ & $47.4 \pm 51.1$ & 0.052 \\
\hline Prothrombin time (PT) (s) & $13.3 \pm 2.9$ & $14.7 \pm 2.0$ & 0.012 \\
\hline Partial thromboplastin time (PTT) (s) & $32.7 \pm 11.6$ & $37.9 \pm 12.2$ & $\mathbf{0 . 0 3 4}$ \\
\hline Internal normalized ratio (INR) & $1.02 \pm 0.17$ & $1.15 \pm 0.4$ & 0.008 \\
\hline NICU day (days) & $8.8 \pm 6.1$ & $13.9 \pm 10.6$ & 0.001 \\
\hline
\end{tabular}

third-generation cephalosporins, and carbapenems (in decreasing order of frequency). Data on the duration of oxygen supplementation or any type of ventilatory support are presented in Table 2 for 47 (26.7\%) infants.

Eight infants underwent lung computerized tomography: three with no findings, four with bilateral findings, and one with unilateral findings (of either consolidation or groundglass opacities). In addition, 14 patients had a positive blood or urine culture for bacterial infection.

Among the 176 cases, $10(5.7 \%)$ were diagnosed with myocarditis based on elevated cardiac enzymes, electrocardiography or echocardiography findings; tachycardia was the only clinical finding in three patients, and fever was present in another three.

When we evaluated the clinical findings, cough (odds ratio [OR]: 9.52, 95\% confidence interval [CI]: 4.17-21.71), tachypnea (OR: 26.5, 95\% CI: 9.59-73.19), and retractions (OR: 27.5, 95\% CI: 5.96-126.96) were associated with more severe clinical disease (Table 4). Also, there were significant differences in the $\mathrm{C}$-reactive protein level, prothrombin time (PT), partial thromboplastin time, international normalized ratio, and days in the NICU $(p=0.002, p=0.012, p=0.034$, $p=0.008$, and $p<0.001$, respectively) between patients with mild-moderate and severe-critical presentations (Table 4). A PT above $14 \mathrm{~s}$ was a significant predictor of severe/critical cases, with a sensitivity of $64 \%$ and specificity of $73 \%$.

One $(0.6 \%)$ patient with Trisomy 21 and an atrioventricular septal defect died due to acute respiratory distress syndrome and sepsis.

\section{Discussion}

We evaluated the demographic characteristics, presentations, laboratory findings, and clinical courses of 176 neonates from 32 cities in Turkey with postnatally acquired COVID19 infection. To the best of our knowledge, this is the largest number of cases reported to date.

Currently, available epidemiological reports of children with COVID-19 have suggested that critical cases are more likely in adolescents than younger children. Children generally have mild symptoms and respiratory disease, fully recover within 1-2 weeks and require minimal supportive care [17-20]. However, neonates must be evaluated and 
treated differently from other children. There have been some neonatal case reports and series differing in severity [21]. In our cohort, we included neonates who required medical help, and were either symptomatic or had a contact history. Almost one quarter of the patients required some type of respiratory support. The high numbers of patients who were symptomatic or needed respiratory support in this study could be due to the study inclusion criteria (the data were obtained only from NICUs, i.e., not from the pediatric emergency room) and flexibility of criteria for hospitalization of neonates, particularly during a new pandemic.

Most of the patients were male term infants with birthweight appropriate for gestational age. Current pediatric epidemiological data indicate that there are more male than female COVID-19 cases [17-20]. Congenital anomalies were detected in four patients: a heart defect, hydronephrosis, Alagille syndrome, and cleft palate. It has been reported that patients with a history of congenital or acquired diseases have greater susceptibility to COVID-19 [17]. Almost half of our patients were born by C-section, which corresponds to Turkish National Population and Health Statistics and our group's previous publication [12].

Horizontal transmission of SARS-CoV-2 to the newborn seems to occur primarily through respiratory droplets when neonates are exposed to mothers or other caregivers with SARS-CoV-2 infection, and may occur more readily than previously thought $[3,22]$. In our study, to further investigate potential sources of infection, family members living within the same house were questioned about their symptoms and given a RT-PCR test. The household contact rate was $77.8 \%$, with $65.9 \%$ of mothers having positive RT-PCR test results, similar to a recent Turkish pediatric study and a previous systematic review [19, 20], but lower than earlier publications claiming family cluster infection rates of $>90 \%$ $[23,24]$. The source of infection was either unknown or someone outside the family in $21 \%$ of our cases, which can be explained by the Turkish tradition of visiting the family of a newborn to welcome the baby and congratulate the new parents. Only two neonates acquired an infection in the NICU, similar to Piersigilli et al. [25].

Of our cases, $90 \%$ were symptomatic, probably due to the inclusion criteria, and in line with the recent report of Karbuz et al. on patients $<1$ year of age [20]. As in all previous reports, fever was the most common symptom in this study, either alone or accompanied by other symptoms $[17-20,26]$. Generally, fever is not frequently seen in neonatal infections, although a systematic review reported fever in $44.3 \%$ of cases, similar to our result and representing a higher rate compared to common neonatal infections [27]. Feeding intolerance was the second most common symptom, and occurred at a much higher than in other series [26-29]. This may be explained by the subjectivity of this symptom. Respiratory symptoms, i.e., cough, tachypnea, retractions, and rhinorrhea, were the main symptoms, as expected, similar to other adult and child series [17-21, 24-28]. Among the respiratory symptoms, cough, retractions, and tachypnea on admission were independent predictors of more severe disease; however, this may be due to our use of the severity classification system of Dong et al. [17]. Diarrhea and neurological symptoms, such as irritability and somnolence, were rare manifestations, similar to other adult and child series, and generally cooccurred with respiratory distress symptoms [18-20, 29]. A rash was the only symptom in three neonates, similar to Bilavski et al. [29].

Myocarditis was the most common complication in our series, and was diagnosed, by the local pediatric cardiologist, based on tachycardia, elevated cardiac enzymes, and decreased cardiac functions on echocardiography (such as poor cardiac contractility). No specific criteria or cut off for the cardiac enzymes were established for the purpose of this study. The adult literature often cites cardiac involvement in COVID-19, including arrhythmias and myocardial injury. The first infant case of myocardial injury due to COVID-19 infection was reported in March 2020 [30]. Another recently published neonatal case report discussed the clinical importance of refracted myocarditis [31]. Even though COVID-19 infection is less common and presents with milder symptoms in pediatric cases, the cases in these reports show that there is some risk of cardiac involvement [30-32].

Our patients with a PT $<14 \mathrm{~s}$ were less likely to have a severe clinical course (e.g., the need for oxygen supplementation or organ failure), similar to our previous report [12]. A long PT may be an initial indication of liver dysfunction due to tissue hypoxia.

During the COVID-19 pandemic, whether neonates should be fed with breastmilk, particularly when the mother is also infected, has been a difficult decision for all pediatricians. Current research indicates that the risk of viral transmission of SARS-CoV-2 through breast milk is low, such that breastfeeding should be encouraged [4]. However, formula feeding occurred in almost a quarter of the infants in our cohort, similar to our previous publication; this can be explained by these cases occurring before the announcement by the WHO pertaining to the safety of breastfeeding [16], and by the cessation of breastfeeding during antiviral treatment of coinfected mothers. Nevertheless, the proportion was high compared to that reported by Trevisanuto et al. [33]. The safety of breastfeeding by mothers with COVID19 infection has been shown by Salvatore et al., who found that all infants tested negative for SARS-CoV-2 at 5-7 and 14 days after birth, including those breastfed by mothers with COVID-19 [4, 34]. The TNS has revised its breastfeeding recommendations accordingly; mothers are now strongly advised to breastfeed [35].

We applied the diagnostic criteria and classification system of Dong et al. [17], as it was the only clinical 
classification system available at the beginning of the pandemic, and was based on a large number of pediatric cases $(N=2135)$. According to this system, almost one quarter of our patients were severe cases, and $4.5 \%$ were critically ill. These rates were higher than those reported by Dong et al. $(1.9 \%)$ for children $<1$ year of age, and in other case series [17, 26, 29], probably due to selection bias in our study. However, our data were similar to Karbuz et al. [20]. Götzinger et al. included 582 children in their multicenter European study, and reported that an age of $<1$ month was associated with an OR for the requirement for NICU admission of 5.06 [36]. Also, Ouldali et al. reported that infants $<3$ months of age accounted for one-third of hospitalized pediatric cases in their prospective study, although only $3 \%$ had severe disease [26]. Most of our cases had uneventful disease courses and rapidly improved with supportive treatment; only one patient died.

Fernandes et al. reported that among 281 pediatric patients hospitalized with SARS-CoV-2 infection, half had respiratory disease, and $41 \%$ were admitted to the intensive care unit; this shows the severity of the cases [37]. They also reported that hypoxia on admission was predictive of severe respiratory disease, as expected. Similarly, we found that cough, tachypnea, and chest retractions were independent predictors of severity.

There have been few reports in the literature of neonatal cases requiring mechanical ventilation [38]. Almost 10\% of the cases in our series received non-invasive ventilation. In an early review of neonatal cases with SARS-CoV-2, the rate of mechanical ventilatory support was $11 \%$ [33]. In the same review, the rate of spontaneous breathing in room air was $75 \%$, similar to our study. However, in some reports in the literature, no symptomatic cases required invasive ventilatory support [29]. In several pediatric case series, the requirement for invasive ventilation was reported to be 10-25\%, although there was large variability in the study inclusion criteria [17, 26, 37]. In our previous report, the supplemental oxygen and non-invasive ventilation rates were relatively high, perhaps due to the inclusion only of RT-PCR test-confirmed symptomatic cases during the early stages of the pandemic.

The management of neonates infected with COVID-19 is based on supportive treatments including supplemental oxygen, respiratory support, fluid resuscitation, and temperature control [13]. The medications most commonly used in our study were intravenous antibiotics, azithromycin, and oseltamivir, in $54 \%, 16.5 \%$, and $8.5 \%$ of cases, respectively. The rate of antibiotic use was much higher in another series, which may be explained by the high prevalence of fever. Moreover, until negative blood cultures are obtained, empiric antibiotic use is routine [29]. The rate of oseltamivir use was similar between our study and that of Hoang et al. [19]. Currently, evidence supporting the use of antiviral medications and steroids for neonatal COVID-19 is lacking [1]. The first report of remdesivir use in a neonatal case was from Frauenfelder et al.; it was used in the fifth week of life in a premature infant with severe acute respiratory failure and systematic deterioration [39].

\section{Conclusions}

We reported the data of 176 symptomatic and hospitalized late-onset COVID-19 neonatal patients. Symptoms were typical of acute respiratory and/or gastrointestinal infections, with fever being the main symptom. Cough, tachypnea, and chest retractions on admission may indicate a severe disease course. Despite hospitalization, supplemental oxygen, and ventilation support, all patients except one had a good outcome.

Acknowledgements Neo-Covid Study Group: Eren Yildiz, Nuriye Aslı Melekoglu, Emel Okulu, Handan Hakyemez Toptan, Ozge Surmeli, Emrah Can, Fatma Hilal Yilmaz, Hilal Ozkan, Ibrahim Caner, Serdar Comert, Saime Sundus Uygun, Sinem Akbay, Asli Memisoglu, Ayse Anik, Baran Cengiz Arcagok, Belma Saygili Karagol, Mehmet Ates, Muhammet Bulut, Mustafa Ali Akin, Nihat Demir, Ramazan Ozdemir, Sema Arayici, Sebnem Kader, Adil Umut Zubarioglu, Ahmet Oktem, Ali Bulbul, Berna Hekimoglu, Emel Ataoglu, Demet Orhan Baser, Emine Esin Yalinbas, Ebru Yalin Imamoglu, Ferda Ozlu, Leyla Bilgin, Melike Kefeli, Meltem Koyuncu Arslan, Selahattin Akar, Handan Bezirganoglu, Senol Bozdag, Resat Gurpinar, Nukhet Aladag Ciftdemir, Ozmert MA Ozdemir

Authors' contributions IMA: conceptualization, writing-original draft, writing - review and editing, read and approved the final manuscript. MKK: conceptualization, acquisition of data, read and approved the final manuscript. CT: conceptualization, acquisition of data, read and approved the final manuscript. MYO: conceptualization, acquisition of data, read and approved the final manuscript. TI: acquisition of data, read and approved the final manuscript. MD: acquisition of data, read and approved the final manuscript. AY: acquisition of data, read and approved the final manuscript. FN: acquisition of data, read and approved the final manuscript. IE: acquisition of data, read and approved the final manuscript. HK: acquisition of data, read and approved the final manuscript. OE: writing-original draft, writing-review and editing, read and approved the final manuscript. EK: writing-review, editing, read and approved the final manuscript.

Availability of data and material We can provide participant data without names and identifiers, but not the study protocol, statistical analysis plan, or informed consent form.

\section{Declarations}

Ethics approval The study was approved by the Rize University School of Medicine local ethics committee and the Ministry of Health.

Consent to participate Written informed consent was obtained from patients.

Consent for publication Not applicable. 
Conflict of interest The authors declare no competing interests.

\section{References}

1. WHO: Coronavirus disease 2019 (COVID-19) situation reports. https://www.who.int/emergencies/diseases/novel-coronavirus2019/situation-reports. Accessed Jun 2021

2. WHO Coronavirus (COVID-19) Dashboard. https://covid19.who. int. Accessed Jun 2021

3. Shah MD, Saugstad OD (2021) Newborns at risk of Covid-19-lessons from the last year. J Perinat Med 49(6):643-649. https://doi.org/10. 1515/jpm-2021-0258

4. Altendahl M, Afshar Y, de St Maurice A, Fajardo V, Chu A (2020) Perinatal maternal fetal/neonatal transmission of COVID-19: a guide to safe maternal and neonatal care in the era of COVID-19 and physical distancing. NeoReviews 21(12):e783-e794

5. Oncel MY, Akın IM, Kanburoglu MK et al (2021) A multicenter study on epidemiological and clinical characteristics of 125 newborns born to women infected with COVID-19 by Turkish Neonatal Society. Eur J Pediatr 180(3):743-744. https://doi.org/10. 1007/s00431-020-03783-5

6. Huntley BJF, Huntley ES, Di Mascio D, Chen T, Berghella V, Chauhan SP (2020) Rates of maternal and perinatal mortality and vertical transmission in pregnancies complicated by severe acute respiratory syndrome coronavirus 2 (SARS-Co-V-2) infection: a systematic review. Obstet Gynecol 136(2):303-312. https://doi. org/10.1097/AOG.0000000000004010

7. Flaherman VJ, Afshar Y, Boscardin J et al (2020) Infant outcomes following maternal infection with SARS-CoV-2: First report from the PRIORITY study. Clin Infect Dis ciaa1411. https://doi.org/10. 1093/cid/ciaa1411

8. Angelidou A, Sullivan K, Melvin PR et al (2021) (2021) Association of maternal perinatal SARS-CoV-2 infection with neonatal outcomes during the COVID-19 pandemic in Massachusetts. JAMA Netw Open 4:e217523. https://doi.org/10.1001/jamanetworkopen. 2021.7523

9. Vivanti AJ, Vauloup-Fellous C, Prevot S et al (2020) Transplacental transmission of SARS-CoV-2 infection. Nat Commun 11(1):3572. https://doi.org/10.1038/s41467-020-17436-6

10. Heinonen S, Helve O, Andersson S, Janer C, Süvari L, Kaskinen A (2021) Nasal expression of SARS-CoV-2 entry receptors in newborns. Arch Dis Child Fetal Neonatal Ed fetalneonatal-2020-321334. https:// doi.org/10.1136/archdischild-2020-321334

11. Lee PI, Hu YL, Chen PY, Huang YC, Hsueh PR (2020) Are children less susceptible to COVID-19? J Microbiol Immunol Infect 53:371-372. https://doi.org/10.1016/j.jmii.2020.02.011

12. Kanburoglu MK, Tayman C, Oncel MY et al (2020) A Multicentered study on epidemiologic and clinical characteristics of 37 neonates with community-acquired COVID- 19. Pediatr Infect Dis J 39(10):e297-e302. https://doi.org/10.1097/INF.0000000000002862

13. Sankaran D, Nakra N, Cheema R, Blumberg D, Lakshminrusimha S (2021) Perinatal SARS-CoV-2 infection and neonatal COVID19: a 2021 update. NeoReviews 22(5):e284-e295. https://doi.org/ 10.1542/neo.22-5-e1001

14. Erdeve Ö, Çetinkaya M, Baş AY, Narlı N, Duman N, Vural M, Koç E (2020) The Turkish Neonatal Society proposal for the management of COVID-19 in the neonatal intensive care unit. Turk Pediatri Ars 55:86-92. https://doi.org/10.14744/TurkPediatriArs. 2020.43788

15. Turkish Ministry of Health (2020) COVID-19 Yeni Koronavirus Hastaligi [Online]. Available at: https://covid19bilgi.saglik.gov. $\operatorname{tr} / \mathrm{tr}$
16. Breastfeeding and COVID-19 (2020) https://www.who.int/newsroom/commentaries/detail/breastfeeding-and-covid-19

17. Dong Y, Mo X, Hu Y, Qi X, Jiang F, Jiang Z, Tong S (2020) Epidemiology of COVID-19 among children in China. Pediatrics 145(6):e20200702. https://doi.org/10.1542/peds.2020-0702

18. Ding Y, Yan H, Guo W (2020) Clinical characteristics of children with COVID-19: a meta-analysis. Front Pediatr 8:431. https://doi. org/10.3389/fped.2020.00431

19. Hoang A, Chorath K, Moreira A, Evans M, Burmeister-Morton F, BurmeisterF NR, Petershack M, Moreira A (2020) COVID-19 in 7780 pediatric patients: a systematic review. EClinicalMedicine 26(24):100433. https://doi.org/10.1016/j.eclinm.2020.100433

20. Karbuz A, Akkoc G, Demirdag B et al (2021) Epidemiological, clini$\mathrm{cal}$, and laboratory features of children with COVID-19 in Turkey. Front Pediatr 7(9):631547. https://doi.org/10.3389/fped.2021.631547

21. Karabay M, Çınar N, Karakaya Suzan Ö, Yalnızoğlu Çaka S, Karabay O (2020) Clinical characteristics of confirmed COVID19 in newborns: a systematic review. J Matern Fetal Neonatal Med 19:1-12. https://doi.org/10.1080/14767058.2020.1849124

22. Blumberg DA, Underwood MA, Hedriana HL, Lakshminrusimha S (2020) Vertical transmission of SARS-CoV-2: What is the optimal definition? Am J Perinatol 37:769-772. https://doi.org/10. 1055/s-0040-1712457

23. Wu Q, Xing Y, Shi L, Li W, Gao Y, Pan S, Wang Y, Wang W, Xing Q (2020) Coinfection and other clinical characteristics of COVID-19 in children. Pediatrics 146(1):e20200961. https://doi. org/10.1542/peds.2020-0961

24. Panahi L, Amiri M, Pouy S (2020) Clinical characteristics of COVID-19 infection in newborns and pediatrics: a systematic review. Arch Acad Emerg Med 18;8(1):e50

25. Piersigilli F, Carkeek K, Hocq C, van Grambezen B, Hubinont C, Chatzis O, Van der Linden D, Danhaive O (2020) COVID19 in a 26-week preterm neonate. Lancet Child Adolesc Health 4(6):476-478. https://doi.org/10.1016/S2352-4642(20)30140-1

26. Ouldali N, Yang DD, Madhi F et al (2021) Factors associated with severe SARS- CoV-2 infection. Pediatrics 147(3):e202002343. https://doi.org/10.1542/peds.2020-023432

27. Raschetti R, Vivanti AJ, Vauloup-Fellous C et al (2020) Synthesis and systematic review of reported neonatal SARS-CoV-2 infections. Nat Commun 11(1):5164. https://doi.org/10.1038/ s41467-020-18982-9

28. Schwartz DA, Mohagheghi P, Beigi B, Zafaranloo N, Moshfegh F, Yazdani A (2020) Spectrum of neonatal COVID-19 in Iran: 19 infants with SARS-CoV-2 perinatal infections with varying test results, clinical findings and outcomes. J Matern Fetal Neonatal Med 12:1-10. https://doi.org/10.1080/14767058.2020.1797672

29. Bilavski HY, Balanson S, Shalabi RD et al (2021) Benign course and clinical features of COVID- 19 in hospitalised febrile infants up to 60 days old. Acta Paediatrica (online ahead of print) 1-6. https://doi.org/10.1111/apa.15993

30. Cui Y, Tian M, Huang D et al (2020) A 55-day-old female infant infected with 2019 novel coronavirus disease: Presenting with pneumonia, liver injury, and heart damage. J Infect Dis 221(11):1775-1781. https://doi.org/10.1093/infdis/jiaa113

31. Precit MR, Yee R, Anand V, Mongkolrattanothai K, Pandey U, Dien Bard J (2020) A case report of neonatal acute respiratory failure due to severe acute respiratory syndrome coronavirus-2. J Pediatric Infect Dis Soc 13;9(3):390-392. https://doi.org/10.1093/ jpids/piaa064

32. Sanna G, Serrau G, Bassareo PP, Neroni P, Fanos V, Marcialis MA (2020) Children's heart and COVID-19: Up-to-date evidence in the form of a systematic review. Eur J Pediatr 179(7):1079-1087. https://doi.org/10.1007/s00431-020-03699-0

33. Trevisanuto D, Cavallin F, Cavicchiolo ME, Borellini M, Calgaro S, Baraldi E (2021) Coronavirus infection in neonates: a systematic 
review. Arch Dis Child Fetal Neonatal Ed 106:330-533. https:// doi.org/10.1136/archdischild-2020-319837

34. Salvatore C, Han J-Y, Acker K et al (2020) Neonatal management and outcomes during the COVID-19 pandemic: an observation cohort study. Lancet Child Adolesc Health 4(10):721-727. https:// doi.org/10.1016/S2352-4642(20)30235-2

35. Erdeve Ö, Çetinkaya M, Baş AY, Narlı N, Duman N, Vural M, Koç E (2020) Author's response. Turk Pediatri Ars 16;55(4):458459. eCollection 2020

36. Götzinger F, Santiago-García B, Noguera-Julián A et al (2020) COVID-19 in children and adolescents in Europe: a multinational, multicentre cohort study. Lancet Child Adolesc Health 4(9):653661. https://doi.org/10.1016/S2352-4642(20)30177-2

37. Fernandes DM, Oliveira CR, Guerguis $S$ et al (2021) Severe acute respiratory syndrome coronavirus 2 clinical syndromes and predictors of disease severity in hospitalized children and youth. $\mathbf{J}$ Pediatr 230:23-31.e10. https://doi.org/10.1016/j.peds.2020.11.016
38. Yakame K, Shoji T, Kanazawa T, Sato M, Kawasaki T (2021) Severe neonatal COVID-19 pneumonia requiring mechanical ventilation. Pediatr Int (Online ahead of print). https://doi.org/ 10.1111/ped.14677

39. Frauenfelder C, Brierley J, Whittaker E, Perucca G, Bamford A (2020) Infant with SARS-CoV-2 Infection causing severe lung disease treated with Remdesivir. Pediatrics 146(3):e20201701. https://doi.org/10.1542/peds.2020-1701

Publisher's Note Springer Nature remains neutral with regard to jurisdictional claims in published maps and institutional affiliations.

\section{Authors and Affiliations}

\section{Ilke Mungan Akin ${ }^{1}$ (D) Mehmet Kenan Kanburoglu ${ }^{2} \cdot$ Cuneyt Tayman $^{3} \cdot$ Mehmet Yekta Oncel $^{4,5}$. Timucin Imdadoglu ${ }^{6} \cdot$ Mustafa Dilek $^{7} \cdot$ Akan Yaman $^{8} \cdot$ Fatma Narter $^{9} \cdot$ Ilkay Er $^{10} \cdot$ Hasan Kahveci $^{11} \cdot$ Omer Erdeve $^{12}$. Esin $\mathrm{Koc}^{13} \cdot$ Neo-Covid Study Group}

Mehmet Kenan Kanburoglu

kanburoglumk@outlook.com

Cuneyt Tayman

ctayman22@gmail.com

Mehmet Yekta Oncel

dryekta@gmail.com

Timucin Imdadoglu

dr.timucini@gmail.com

Mustafa Dilek

mustafadilek@gmail.com

Akan Yaman

akan.yaman@nisantasi.edu.tr

Fatma Narter

fatmakaya06@yahoo.com.tr

Ilkay $\mathrm{Er}$

ilkayer7778@yahoo.com

Hasan Kahveci

drhasankahveci@hotmail.com

Omer Erdeve

omererdeve@yahoo.com

Esin Koc

dr.esin.koc@hotmail.com

1 Division of Neonatology, Umraniye Training and Research Hospital, University of Health Sciences, Istanbul, Turkey

2 Division of Neonatology, Department of Pediatrics, School of Medicine, Rize Recep Tayyip Erdogan University, Rize, Turkey

3 Division of Neonatology, Ankara City Hospital, Ministry of Health, Ankara, Turkey
4 Division of Neonatology, Department of Pediatrics, School of Medicine, İzmir Katip Celebi University, Izmir, Turkey

5 Division of Neonatology, Tepecik Training and Research Hospital, University of Health Sciences, Izmir, Turkey

6 Division of Neonatology, Sancaktepe Training and Research Hospital, University of Health Sciences, Istanbul, Turkey

7 Division of Neonatology, Department of Pediatrics, School of Medicine, Abant Izzet Baysal University, Bolu, Turkey

8 Division of Neonatology, Department of Pediatrics, School of Medicine, Nisantasi University, Istanbul, Turkey

9 Division of Neonatology, Ministry of Health Kartal Dr. Lutfi Kirdar City Hospital, Istanbul, Turkey

10 Division of Neonatology, Kocaeli Derince Training and Research Hospital, University of Health Sciences, Kocaeli, Turkey

11 Division of Neonatology, Department of Pediatrics, Erzurum Bolge Hastanesi, University of Health Sciences, Erzurum, Turkey

12 Division of Neonatology, Department of Pediatrics, School of Medicine, Ankara University, Ankara, Turkey

13 Division of Neonatology, Department of Pediatrics, School of Medicine, Gazi University, Ankara, Turkey

14 Department of Pediatrics, School of Medicine, Kastamonu University, Kastamonu, Turkey

15 Division of Neonatology, Department of Pediatrics, School of Medicine, Malatya Turgut Ozal University, Malatya, Turkey

16 Division of Neonatology, Zeynep Kamil Training and Research Hospital, University of Health Sciences, Istanbul, Turkey 
17 Division of Neonatology, Department of Pediatrics, School of Medicine, Eskisehir Osmangazi University, Eskisehir, Turkey

18 Division of Neonatology, Bagcilar Training and Research Hospital, University of Health Sciences, Istanbul, Turkey

19 Division of Neonatology, Konya Dr Ali Kemal Berivanli Obstetrics and Children's Hospital, Konya, Turkey

20 Division of Neonatology, Department of Pediatrics, School of Medicine, Uludag University, Bursa, Turkey

21 Division of Neonatology, Department of Pediatrics, School of Medicine, Sakarya University, Sakarya, Turkey

22 Division of Neonatology, Istanbul Training and Research Hospital, University of Health Sciences, Istanbul, Turkey

23 Division of Neonatology, Ministry of Health Kahramanmaras Necip Fazil City Hospital, Kahramanmaras, Turkey

24 Division of Neonatology, Manisa City Hospital, Manisa, Turkey

25 Division of Neonatology, Department of Pediatrics, School of Medicine, Marmara University, Istanbul, Turkey

26 Division of Neonatology, Department of Pediatrics, School of Medicine, Aydin Adnan Menderes University, Aydin, Turkey

27 Division of Neonatology, Department of Pediatrics, School of Medicine, Acibadem University, Istanbul, Turkey

28 Division of Neonatology, Department of Pediatrics, Gulhane Medical School, University of Health Sciences, Ankara, Turkey

29 Division of Neonatology, Department of Pediatrics, Ege University, Izmir, Turkey

30 Department of Pediatrics, School of Medicine, Giresun University, Giresun, Turkey

31 Division of Neonatology, Department of Pediatrics, School of Medicine, Samsun 19 Mayis University, Samsun, Turkey

32 Division of Neonatology, Ozel Esencan Hospital, Istanbul, Turkey

33 Division of Neonatology, Department of Pediatrics, School of Medicine, Malatya Inonu University, Malatya, Turkey

34 Division of Neonatology, Ministry of Health Eskisehir City Hospital, Eskisehir, Turkey

35 Division of Neonatology, Department of Pediatrics, School of Medicine, Karadeniz Technical University, Trabzon, Turkey
36 Division of Neonatology, Department of Pediatrics, School of Medicine, Gaziosmanpasa Hospital, Yeni Yuzyıl University,, Istanbul, Turkey

37 Division of Neonatology, Sami Ulus Training and Research Hospital, University of Health Sciences, Ankara, Turkey

38 Division of Neonatology, Sisli Etfal Training and Research Hospital, University of Health Sciences, Istanbul, Turkey

39 Division of Neonatology, Trabzon Kanuni Training and Research Hospital, University of Health Sciences, Trabzon, Turkey

40 Division of Neonatology, Haseki Training and Research Hospital, University of Health Sciences, Istanbul, Turkey

41 Division of Neonatology, Batman Obstetric and Children's Hospital, Batman, Turkey

42 Division of Neonatology, Evliya Celebi Training and Research Hospital, University of Health Sciences, Kutahya, Turkey

43 Division of Neonatology, Goztepe Training and Research Hospital, İstanbul Medeniyet University, Istanbul, Turkey

44 Division of Neonatology, Department of Pediatrics, School of Medicine, Cukurova University, Adana, Turkey

45 Division of Neonatology, Department of Pediatrics, Istanbul School of Medicine, Istanbul University, Istanbul, Turkey

46 Division of Neonatology, Buca Seyfi Demirsoy Training and Research Hospital, Izmir Demokrasi University, Izmir, Turkey

47 Division of Neonatology, Department of Pediatrics, School of Medicine, Adiyaman University, Adiyaman, Turkey

48 Division of Neonatology, Diyarbakir Gazi Yasargil Training and Research Hospital, University of Health Sciences, Diyarbakir, Turkey

49 Division of Neonatology, Department of Pediatrics, School of Medicine, Istanbul Okan University, Istanbul, Turkey

50 Division of Neonatology, Department of Pediatrics, School of Medicine, Kocaeli University, Edirne, Turkey

51 Department of Pediatrics, School of Medicine, Trakya University, Edirne, Turkey

52 Division of Neonatology, Department of Pediatrics, School of Medicine, Pamukkale University,, Denizli, Turkey 